\title{
Quantitative immunohistochemical method for detection of wheat protein in model sausage
}

\author{
Zuzana Řezáčová Lukášková ${ }^{1}$, Matej Pospiech ${ }^{1}$, Bohuslava Tremlová ${ }^{1}$, Eva Renčová2, \\ Michaela Petrášová ${ }^{1}$
}

${ }^{1}$ University of Veterinary and Pharmaceutical Sciences Brno, Faculty of Veterinary Hygiene and Ecology, Department of Hygiene and Technology of Vegetable Foodstuff, Brno, Czech Republic

${ }^{2}$ Veterinary Research Institute, Brno, Czech Republic

Received August 29, 2014

Accepted April 1, 2015

\begin{abstract}
Since gluten can induce coeliac symptoms in hypersensitive consumers with coeliac disease, it is necessary to label foodstuffs containing it. In order to label foodstuffs, it is essential to find reliable methods to accurately determine the amount of wheat protein in food. The objective of this study was to compare the quantitative detection of wheat protein in model sausages by ELISA and immunohistochemical methods. Immunohistochemistry was combined with stereology to achieve quantitative results. High correlation between addition of wheat protein and compared methods was confirmed. For ELISA method the determined values were $\mathrm{r}=0.98, P<0.01$; for stereologythe determined values were $\mathrm{r}=0.94, P<0.01$. Although ELISA is an accredited method, it was not reliable, unlike immunohistochemical methods (stereology SD = 3.1).
\end{abstract}

Food allergens, gluten/gliadin, identification, histochemistry, meat products

During food production, various proteins of plant origin are added. They have many positive attributes but on the other hand, plant proteins include a wide range of allergens (Sicherer et al. 1999). One of the most common allergens is wheat protein (gluten) which consists of prolamine proteins and glutelins. Gluten is not only used in vegetable foodstuffs but also in meat products where it improves viscoelastic properties, colour stability, solidity, sappiness, and waterretention capacity of the product (Day et al. 2006). It also decreases cooking loss and positively influences structural and sensory characteristics of the product. However, gluten can induce coeliac symptoms in hypersensitive consumers with the coeliac disease (life-long autoimmune disease) which can have symptoms such as urticaria, atopic dermatitis, diarrhoea, tiredness, bone pains, stomach-aches, loss of appetite, loss of weight, anaemia, osteoporosis, infertility, and mental problems (Hischenhuber et al. 2006). The upper limit of the reported amount $\left(100 \mathrm{mg} \cdot \mathrm{kg}^{-1}\right)$ equals to the upper limit of allowable amount of gluten in gluten-free foodstuffs stipulated in the Commission Regulation (EC) No. 41/2009, concerning the composition and labelling of foodstuffs suitable for people intolerant to gluten. For the purposes of inspection of compliance with legislation, foodstuff quality and for consumers' health protection, research verifying and developing reliable and, if possible, fast quantitative methods with the detection limit of $100 \mathrm{mg} \cdot \mathrm{kg}^{-1}$ is essential (P o ms et al. 2004).

The main aim of this study was to compare the applicability of available quantitative methods, namely the immunochemical method ELISA and stereological analysis of immunohistochemical method in model meat products with known composition. The main criteria of the evaluated procedures were the reliability and sensitivity of the individual methods. With regard to the fact that the amount of allergen inducing an allergic reaction is specific for each individual (Stern et al. 2001), an important monitored aspect was the reliability of detection of both high and low concentrations of added wheat protein. 
Preparation of model meat products

\section{Materials and Methods}

Model meat products were manufactured at the Department of Meat Hygiene and Technology in compliance with commonly available recipes for the Czech Republic (Šedivý 1998). The product was a cooked sausage kabanos in several variants: with no additive (control), and with the additives of $1000,5000,15000$, and 30000 $\mathrm{mg} \cdot \mathrm{kg}^{-1}$ of edible pure wheat protein (Krnovská škrobárna spol. s r. o., Krnov, Czech Republic).

\section{Sample treatment and preparation}

Six samples at the size of $1 \mathrm{~cm}^{3}$ were taken from model meat products. The sampling was done from predetermined locations ( $1^{\text {st }}$ edge, middle, and $2^{\text {nd }}$ edge of the piece of sausage, always from the centre and under-casing layer). Samples were embedded into paraffin blocks in Paraplaste (RNDr. Jan Kulich, Ltd., Prague, Czech Republic); these were cut to $4 \mu \mathrm{m}$ sections at rotation microtome (Leica Microsystems GmbH, Wetzlar, Germany). Each sample was cut into 72 sections ( 24 slides with three sections each), with $50 \mu$ m always trimmed between sections. The sections were spread on water surface and mounted on slides SuperFrost plus (MenzelGläser, Menzel GmbH \& Co KG, Braunschweig, Germany). After taking samples for histological analysis, $250 \mathrm{~g}$ of the sample was frozen for ELISA analysis.

\section{Immunohistochemical (IHC) examination}

For IHC examination of samples, procedure by Řezáčová-Lukášková (2010) was used. It is a sandwich indirect three-stage method which uses high bond affinity between avidin and biotin for antigen detection. As primary antibodies, polyclonal anti-gliadin isolated from a rabbit (Sigma-Aldrich Company, St. Louis, USA) were used. The secondary antibodies, anti-rabbit (Vector Laboratories, PK 6101, Burlingtone, USA) conjugated with biotin was used. The third stage, ABC reagent (VectorLaboratories, PK 6101, Burlingtone, USA) was used for signal amplification. After IHC processing, section backgrounds were stained by toluidine blue (Flint 1994). Identification of wheat protein was performed based on its brown colour and morphological structure.

\section{Stereological analysis}

For quantitative analysis, all sections (432) of model meat products with $15000 \mathrm{mg} \cdot \mathrm{kg}^{-1}$ (72 sections from each predetermined locations) and 72 sections of other concentrations were scanned by NIKON LS-900 ED (Fuji Bldg, Tokyo, Japan) and then examined by Stereological Line System in Ellipse software ver. 2.0.7.1 (ViDiTo, Slovakia) with the grid range of $150 \times 150$ for samples with the addition of 15000 and $30000 \mathrm{mg} \cdot \mathrm{kg}^{-1}$, $100 \times 100$ for samples with the addition of $5000 \mathrm{mg} \cdot \mathrm{kg}^{-1}$, and $80 \times 80$ for samples with the addition of 1000 $\mathrm{mg} \cdot \mathrm{kg}^{-1}$ wheat protein in compliance with the procedure stated by Flint and Meech (1978). The grid was selected with regard to the amount and size of protein aggregates in the sections. The number of sections was examined with regard to the possibility to determine the minimum number of sections required to reliably quantify the added wheat protein. In case of losses and significant damage during processing, the amount necessary for examination was complemented. Results were processed by Excel 2010 (Microsoft Corporation, USA). According to Cavalieri estimator (How ard and Reed 1998) a minimum number of examined sections necessary for quantitative analysis was determined with the probability of coefficient of sampling error $(\mathrm{CE})<0.2$. To verify the proposed procedure of quantification of added amount of wheat protein, 8 randomly selected sections (from each predetermined locations, in total 56) for each concentration of model meat products were then examined by measuring the total wheat protein area compared to the total area of thesample. For a random selection of sections, a web application Random Integer Generator was used (Haahr and Haahr 2014).

\section{ELISA method}

Model meat samples with gliadin were simultaneously analysed using the accredited indirect competitive ELISA method for detection of wheat proteins (gliadin) modified in an accredited laboratory registered with the Czech Institute for Accreditation under No. 1354 at the Veterinary Research Institute (VRI). The analysis was performed using an appropriate standard operating procedure of SOP 1/03-03/A. ELISA was conducted utilising $100 \mu \mathrm{l}$ well system with the application of solid-phase wheat gliadin antigen followed by the addition of sample extracts and the monoclonal mice BALB/C anti-gliadin antibody of own provenance and peroxidase-labelled swine anti-mouse conjugated antibody and tetramethylbenzidine substrate. The measurement of final absorbance was executed at $450 \mathrm{~nm}$. For comparison of these ELISA methods, the model meat products were also examined by diagnostic kit Alert for Gliadin (Neogen Corporation, 620 Lesher Place, Lansing, MI 48912, USA) in the accredited examination laboratory No. 1129 of State Veterinary Institute in Jihlava (SVI).

\section{Determining the density of wheat proteins}

To convert the area percentage into weight percentage, the density of swollen wheat protein was measured. One gram of wheat protein was soaked in $10 \mathrm{ml}$ of $2 \% \mathrm{NaCl}$ solution for $1.5 \mathrm{~h}$. Excessive solution was filtered away and the swollen wheat protein was placed into a $10 \mathrm{ml}$ graduated cylinder filled with $5 \mathrm{ml}$ of water. Subsequently, wheat protein density was calculated as the ratio of weighed amount of protein to the total volume of the gel $(\rho=\mathrm{m} / \mathrm{V})$. For the meat product, density was also determined by weighing $1 \mathrm{~g}$ of the product and measuring its volume. Each volume measurement was performed for three equally prepared samples and the results were averaged. 
Statistical evaluation

Statistical evaluation was performed by means of statistical software of UNISTAT 6.1 (UNISTAT Ltd. 2012, Czech Republic). Pearson's correlation coefficient was used to assess the relation between the compared methods of quantitative examination. Precision (accuracy) of measurement is expressed as standard deviation of the all 56 measurement. Predetermined locations were evaluated by paired Student's $t$-test with a graphical representation using box and whiskers plots.

\section{Results}

For a comparison of results with real addition of wheat proteins and results provided by ELISA method (weight percentage), wheat protein content in the sample in area percentage was determined by point grid. Volume estimate was converted from area percetage (S) value according to Cavalieri principle (Howard and Reed 1998) to volume percentage (V) estV $=4 *(\mathrm{~S} 1+\mathrm{S} 2+\ldots+\mathrm{Sn})\left[\mu \mathrm{m}^{3}\right]$. Estimate weight percentage was converted from the determined density. The density of kabanos sausage was determined as $0.96\left[\mathrm{~g}^{\cdot} \mathrm{cm}^{-3}\right](1 \mathrm{~g}$ of kabanos sausage had $\left.1.05 \mathrm{~cm}^{2}\right)$, and the density of wheat protein was determined as $0.48 \pm$ $0.01\left[\mathrm{~g} \cdot \mathrm{cm}^{-3}\right]\left(\mathrm{n}=10 ; 1 \mathrm{~g}\right.$ of wheat protein had $\left.2.1 \mathrm{~cm}^{2}\right)$.

For model meat products with the addition of $15000 \mathrm{mg} \cdot \mathrm{kg}^{-1}$ wheat protein, all 432 sections were subjected to quantitative evaluation using immunohistochemistry combined with stereology. Variability caused by selecting microscopic image fields was eliminated using the whole scanned sections. The minimum number of sections required for quantitative analysis of the product providing results with acceptable error was set up, so that $\mathrm{CE}$ based on sampling intensity was less than 0.2 (Fig. 1) according to the criterion of time-consumption as well as required precision of the determination $\mathrm{CE}$ show the precision of the estimate stereological methods. The CE decreased with the number of examined slides (Fig. 1) but also with the amount of wheat protein addition (Fig. 2). The CE was calculated to determine the appropriate number and size of disector counting frames. The $\mathrm{CE}$ is the variation in sampling within each individual and reflects the precision based on how intensely each individual is sampled. The CE may be improved by sampling more sections within each individual or sampling more disector sites within each section (Gundersen et al. 1999).

Although for qualitative determination of the presence of $1000 \mathrm{mg} \cdot \mathrm{kg}^{-1}$ of wheat protein with a probability greater than $99 \%$, investigation of three samples is sufficient (Řezáčová-Lukášková et al. 2011); the minimum number of sections required for all

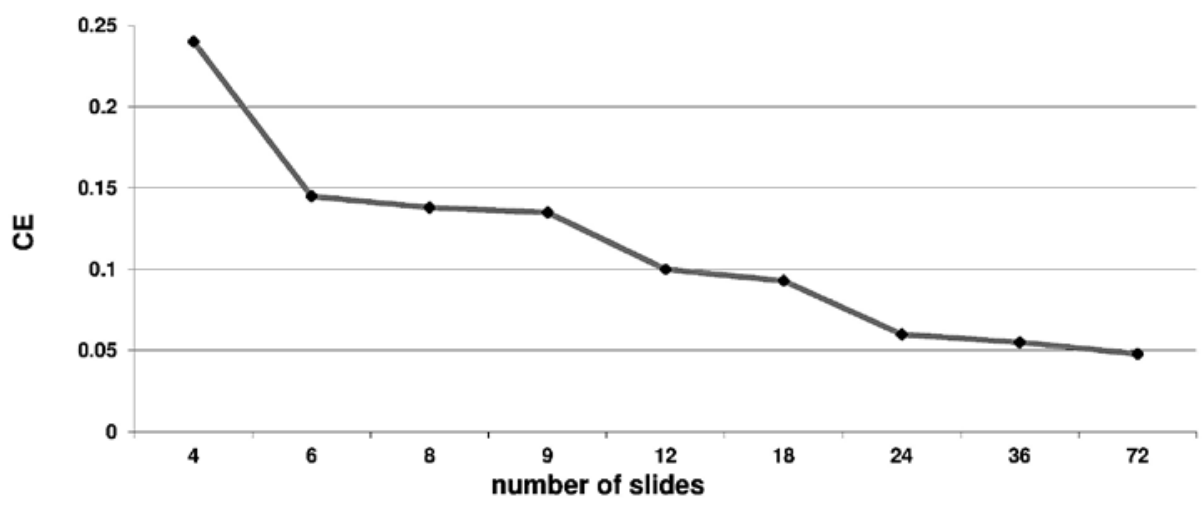

CE coefficient of sampling error

Fig. 1. Dependence of coefficient of sampling error to sections number of the product with the addition of wheat protein at a concentration of $15000 \mathrm{mg} \cdot \mathrm{kg}^{-1}$ 


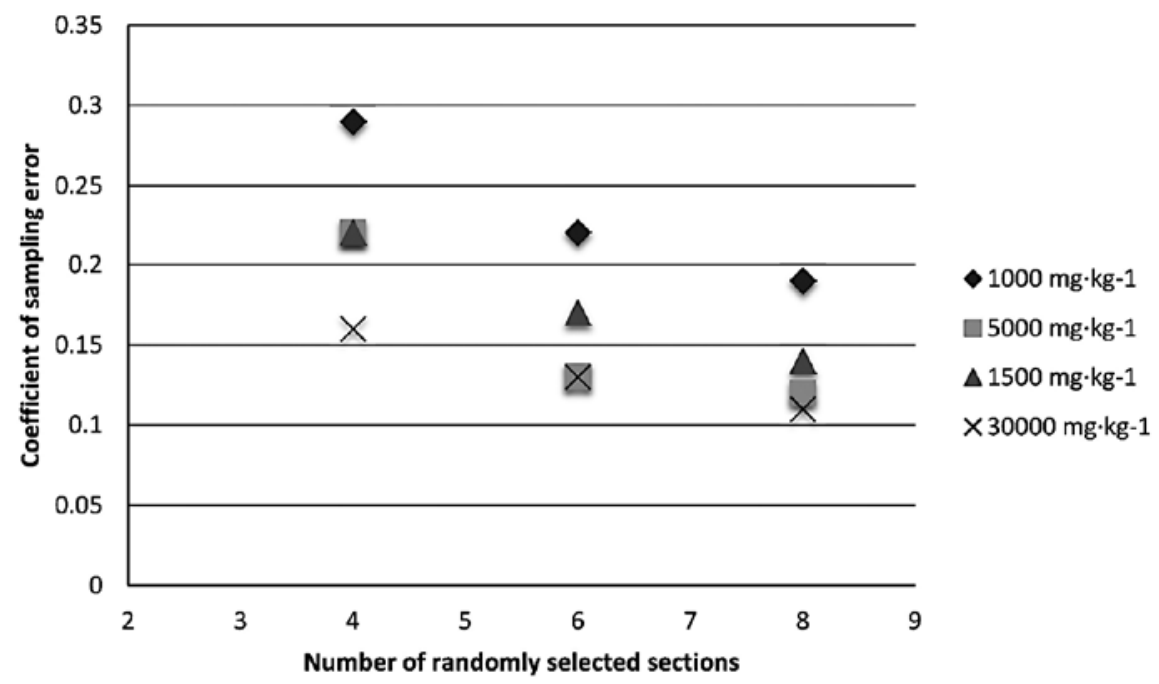

Fig. 2. Coefficient of sampling error of stereological assessment of 4, 6 and 8 randomly selected sections from different sampling points of the product and with different amount of gluten

groups of samples to be investigated for quantitative analysis with $\mathrm{CE}<0.2$ was set to 8 (Fig. 2).

The difference of wheat protein contained in predetermined locations ( $1^{\text {st }}$ edge, middle, and $2^{\text {nd }}$ edge of the piece of sausage, always from the centre and under-casing layer) on the result of the quantitative examination was not confirmed (Plate III, Fig. 3). Also comparison of paired $t$-test indicated no significant differences between the results of examination of various predetermined locations $(P>0.05)$. All quantitative results were compared with the results obtained by ELISA VRI and SVI (Table 1).

All the compared methods were evaluated using Pearson's correlation coefficient. Based on this evaluation, a close correlation between ELISA and stereology $(\mathrm{r}=0.97, P<0.01)$ was found. All compared methods showed highly significant correlation with the wheat protein addition percentage. For the ELISA method values of $\mathrm{r}=0.98, P<0.01$, and stereology $\mathrm{r}=0.94, P<0.01$ were determined (Table 1 ).

Table 1. Amount of wheat protein $\left(\mathrm{mg} \cdot \mathrm{kg}^{-1}\right)$ in model meet product measured by different methods.

\begin{tabular}{lccccccc}
\hline Method used & \multicolumn{4}{c}{ Addition of wheat protein } & & Precision (SD) & Pearson's $r^{2}$ \\
\hline & 0 & 1000 & 5000 & 15000 & 30000 & 0.001 \\
ELISA (SVI) & $<3.00^{*}$ & $53.50^{* *}$ & 350 & 613 & 988 & N/A & 0.98 \\
ELISA (VRI) & - & - & + & ++ & +++ & N/A & N/A \\
IHC & 0 & 220 & 955 & 2465 & 2845 & 3.100 & 0.94 \\
\hline
\end{tabular}

* product meets the requirements for gluten-free foods and ingredients, gluten value $<20.00 \mathrm{mg} \cdot \mathrm{kg}^{-1} ; * *$ product meets the requirements for gluten-free foods and ingredients, gluten value is $<100.00 \mathrm{mg} \cdot \mathrm{kg}^{-1}$; + positive result (amount of crosses indicates the estimated quantity of wheat protein); - negative result; N/A not available, IHC immunohistochemical methods, SVI State Veterinary Institute, VRI Veterinary Research Institute 


\section{Discussion}

Koolmees and Bijker (1985) previously compared the advantages and disadvantages of histometrical and chemical methods to quantify the proportion of collagenous tissue in meat products. The advantage of histometrical examination was obtaining more comprehensive information about the composition of the product, which corresponded with the results of this work. On the other hand, using the ELISA method, it is possible to investigate a large number of samples simultaneously in a favourable period of time without expensive laboratory equipment (Renčová and Tremlová 2009). In both cases there are differences between the total content of added wheat protein and the detected content (Table 1). The differences are mainly caused by the principle behind both methods. For the ELISA method a monoclonal antibody was used. In contrast, for the IHC methods a polyclonal antibody was used. All used antibodies reacted with specific protein epitopes which can be different for both methods. However, the detection of concrete epitopes is not necessary for detection of wheat proteins in terms of macromolecules. As reported by Brehmer et al. (1999), the detection limit depending on the monitored ingredient is alrady from $250 \mathrm{mg} \cdot \mathrm{kg}^{-1}$, whereas the detection limit for the immunohistochemical detection of wheat protein in meat products was set at a concentration of $1000 \mathrm{mg} \cdot \mathrm{kg}^{-1}$. Lower additions were not included due to technological reasons. Thus, this method fails to comply with the generally valid agreement on the detection limit for food allergens which is within the concentration range of $1-100 \mathrm{mg} \cdot \mathrm{kg}^{-1}$, depending on the type of allergen or on analytical possibilities (Koppelman and Hafle 2006). It even fails to meet the range recommended by Hischenhuber et al. (2006) for methods used to inspect gluten-free foodstuffs (10$200 \mathrm{mg} \cdot \mathrm{kg}^{-1}$ depending on the foodstuff and ingredients). However, sensitivity of the ELISA method, as stated by Brehmer et al. (1999), was not confirmed in this study for wheat protein. Based on the examination of samples by ELISA, both samples with the addition of $1000 \mathrm{mg} \cdot \mathrm{kg}^{-1}$ were evaluated as gluten-free. Inaccurate quantification in heat-treated products by ELISA may be due to reduced availability of antigen after the technological processing of the product. For these reasons, the accredited examination laboratory in Jihlava might obtain quantified results that are significantly different from the weighed amount of wheat protein in the sample. In immunohistochemical methods associated with stereology, these errors are minimised through the evaluation by an assessor who can support his/her evaluation with knowledge of the morphological structure of wheat proteins in case of a weaker immune response. On the other hand, quantitative results obtained by the processing of acquired image (stereology) were affected by differences in the intensity of signal amplification that were recorded in the examination of all sections, even though the same protocol for sample processing and analysis was utilised. These differences in the monitored result may be due to the fact that the examination is carried out manually, influenced by the sample processing technique. In case of application of these stereological methods in practice in a commercial laboratory, the effect of manual preparation, personal errors and time consumption can be minimised by automatic equipment for immunohistochemical detection.

A strong correlation between the addition of wheat protein and all the compared methods was confirmed by Pearson's correlation coefficient within the range of $\mathrm{r}^{2}=0.94$ to 0.98 . But in case of low content of wheat protein, the samples analysed by ELISA were incorrectly evaluated as gluten-free. Immunohistochemistry evaluated all samples with additions of wheat protein correctly as food with gluten. For immunohistochemical methods, the number of sections was determined at 8 with $\mathrm{CE}$ less than 0.2 without dependence on location of sampling.

Based on the results of this work, immunohistochemical methods can be recommended. Immunohistochemical method showed greater accuracy $(\mathrm{SD}=3.1)$. Its disadvantage, 
however, is the time-consuming processing of samples that can be reduced by adjusting the working protocols and automation. Differences between sampling points that could affect reliability of the results were not detected. The resulting protocol can be modified to meet the needs of detection of other allergenic proteins in meat products or other food commodities.

\section{Acknowledgements}

This work was supported by the project of NAZV No. 1B53004, Research Plan of Veterinary Aspects of Foodstuffs Safety and Quality (MŠMT No. 6215712402) and the project of IGA VFU 2009 No. 206/2009/VFU.

\section{References}

Brehmer H, Schleicher S, Borowski U 1999: Determination of soya protein, pea protein and gluten in frankfurter - type sausages by means of an enzyme-linked-immunosorbent-assay (ELISA). Fleischwirtschaft 79: 74-78

Commission Regulation (EC) No. 41/2009 of 20 January 2009 concerning the composition and labelling of foodstuffs suitable for people intolerant to gluten. OJ L 16, 21.1.2009, p. 3-5

Day L, Augustin MA, Batey IL, Wrigley CW 2006: Wheat-gluten uses and industry needs. Trends Food Sci Tech 17: $82-90$

Flint OF 1994: Food microscopy: a manual of practical methods, using optical microscopy. Microscopy handbooks. BIOS Scientific Publishers Limited, Oxford, 30 p.

Flint OF, Meech MV 1978: Quantitative determination of texturised soya protein 364 by a stereological technique. Analyst 103: 252-258

Gundersen HJG, Jensen EBV, Kieu V, Nielsen J 1999: The efficiency of systematic sampling in stereologyreconsidered. J Microsc-Oxford 3: 199-211

Haahr M, Haahr S. Random. org. Random Integer Generator Web site. Available at: www. random. org/integers/. Last modified 2014. Accessed August 2, 2014

Hischenhuber C, Crevel R, Jarry B, Mäkis M, Moneret-Vautrin DA, Romano A, Troncone R, Ward R 2006: Review article: safe amounts of gluten for patients with wheat allergy or coeliac disease. Aliment Pharmacol Ther 23: 559-575

Howard CV, Reed MG 1998: Unbiased stereology. UK: BIOS Scientific Publishers, Liverpool, 246 p.

Koolmees PA, Bijker PG 1985: Histometric and chemical methods for determining collagen in meats. Vet Quart 7: $84-90$

Koppelman SJ, Hafle SL 2006: Detecting allergens in food. New York, Woodhead Publishing Limited Cambridge, England, $450 \mathrm{p}$.

Poms RE, Klein CL, Anklam E 2004: Methods for allergen analysis in food: a review. Food Addit Contam 21: $1-31$

Renčová E, Tremlová B 2009: ELISA method for detection of soya proteins in meat products. Acta Vet Brno 78: 667-671

Řezáčová-Lukášková Z, Tremlová B, Pospiech M, Renčová E, Randulová Z 2010: Immunohistochemical detection of wheat protein in model samples. Czech J Food Sci 28: 514-519

Řezáčová-Lukášková Z, Tremlová B, Pospiech M, Renčová E, Randulová Z, Steinhauser L, Reichová A, Bednáŕ J 2011: Comparison of immunohistochemical, histochemical and immunochemical methods for the detection of wheat protein allergens in meat samples and cooked, dry, raw and fermented sausage samples. Food Addit Contam: Part A 28:7

Sicherer SH 1999: Food allergy: When and how to perform oral food challenges. Pediatr Allergy Immunol 10: 226-234

Stern M, Ciclitira PJ, van Eckert R, Feighery C, Janssen FW, Méndez E, Mothes T, Troncone R, Wiesner H 2001: Analysis and clinical effects of gluten in coeliac disease. Eur J Gastroenterol Hepatol 13: 741-747

Šedivý V 1998: Consumer standards for meat products (in Czech). OSSIS, Tábor, 319 p. 
Plate III

Řezáčová Lukášková Z. et al.: Quantitative ... pp. S71-S76

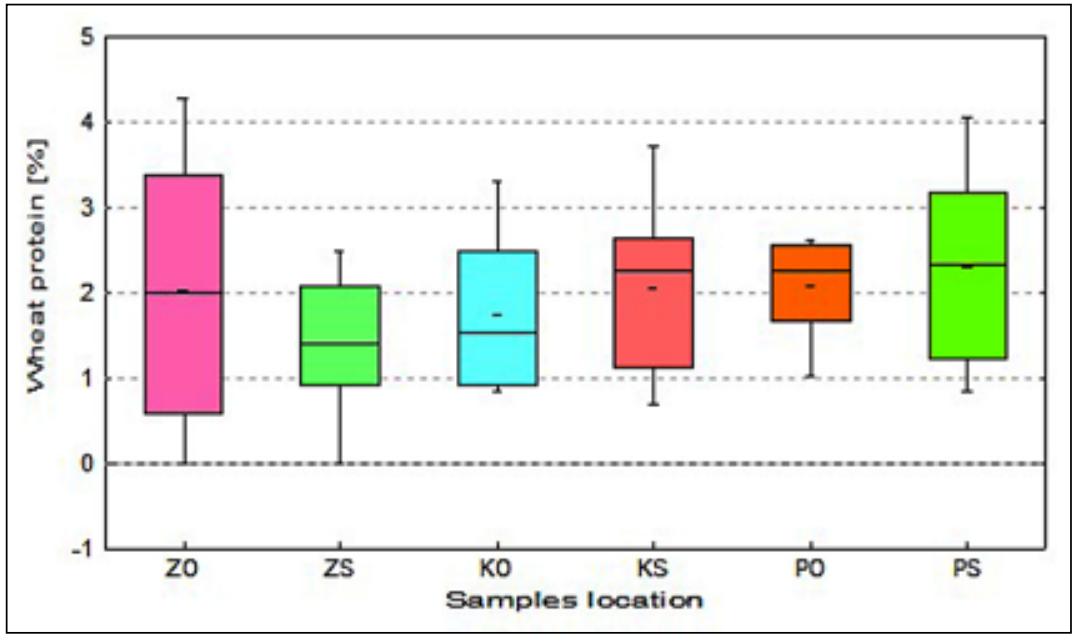

$\mathrm{ZO}-1^{\text {st }}$ edge, under-casing layer; $\mathrm{ZS}-1^{\text {st }}$ edge, centre; KO - $2^{\text {nd }}$ edge, under-casing layer; KS - $2^{\text {nd }}$ edge, centre; PO - middle of the product, under-casing layer; PS - middle of the product, centre

Fig. 3. Comparison of wheat protein content from different samples location by stereology method 